\title{
The Curious Case of the Khettarama Pitch
}

\section{U.P. Nawagamuwa, A.I.M.J. Senanayake and S.A. Silva}

\begin{abstract}
During the Compaq Cup tournament in Sri Lanka in September 2009, the teams batting under lights at the R. Premadasa (Khettarama) Stadium pitch consistently found it very difficult to bat and thus lost matches. Many were of the view that the pitch was helping bowlers a lot more during the evening making it very unfair for the team batting second. This paper is based on the study which was carried out by the authors at the request of Sri Lanka Cricket (SLC) to investigate the behaviour of the R. Premadasa Stadium (Khettarama) pitch. The study aimed to find out if there was any truth to the above claim by conducting insitu bounce tests and collecting top-dressing samples from the pitch at regular time intervals. The test was conducted during the hours of a normal day/night One Day International match would be played at this stadium and match conditions were simulated as far as possible. The variation of bounce with time was then compared with the moisture variation through the course of duration of play to see whether there were correlations between the two. Further, a theoretical discussion based on unsaturated soil mechanics and soil science on the effect of these factors is also included for better understanding.
\end{abstract}

Keywords: Khettarama, bounce, moisture content

\section{Introduction}

Cricket is a game of uncertainty. Whether it be a professional player or a casual fan this is one aspect of cricket which one learns to accept very early on. This inherent uncertainty is present in almost every facet of the game and pitches it seens, are not immune to this. There have been many instances where badly behaving pitches have put a damper on matches. Sri Lanka has always managed to produce well behaved pitches (albeit a slow and low) and this is a testament to the expertise and the hard work of our curators and groundsmen. However, a strange thing happened during the triangular series between Sri Lanka, India and New Zealand for the Compaq Cup in September 2009 at R. Premadasa Stadium.

Named after former Sri Lankan President Ranasinghe Premadasa, the $R$ Premadasa Stadium in Colombo, was built on swamplands adjacent to the Khettarama Temple. The biggest cricket stadium in Sri Lanka till date, the 'Khettarama Stadium', as it was referred to previously, is only one of three Sri Lankan venues to have hosted World Cup matches. Chasing under lights has become extremely difficult in the last four years or so at $R$. Premadasa Stadium and the captains who win the toss have gone onto win a massive percentage of matches.

\section{Erratic bounce on the pitch}

There were four matches played in this Compaq Cup tournament and out of these four, three were won by the team batting first. One can see that this is not something to be alarmed over but, when a closer look is taken at the progress of each match a very unnerving pattern of play emerged. The team batting first scored a big total on a pitch that was very much conducive to batting although a bit slow. The team chasing started off well but at a certain stage of the match the nature of the pitch changed causing batting on it to become markedly more difficult. The only match which panned out differently was the New Zealand vs India match which India won chasing after restricting New Zealand for a meagre 155 all out.

It was the commentators who brought up this issue first and cricket fans immediately jumped on the bandwagon and started saying that there was something awry about the pitch. On the day of the final everybody was saying the toss would be the most crucial part of the match as the team which won the toss would bat first

Eng. (Dr.) U.P. Nawagamuwa, B.Sc. Eng. (Moratuwa), M.Eng. (AIT), Dr. Eng. (YNU), CEng, MIE (Sri Lanka), Senior Lecturer, Department of Civil Engineering, University of Moratuwa, Sri Lanka

Eng.A.I.M.J. Senanayake, BSc.Eng, AMIE (Sri Lanka), Graduate student, Texas Tech University, Texas, USA Eng.S.A. Silva, BSc.Eng, AMIE (Sri Lanka), Graduate student, Department of Civil Engineering, University of Moratuwa, Sri Lanka 
and have a distinct advantage. All predictions were for the team batting first to score a big total and the team batting second to collapse in a heap in the middle part of the chase. Of course, if the final inatch turned out to be different this paper would not have been written but as fate would have it, the match followed the script to the letter.

\section{The Investigation}

The Khettarama grounds were constructed in the $1980 \mathrm{~s}$ on a swampland next to the Khettarama temple and the first match was played in February 1986 [1]. According to SLC sources the pitches on the grounds were very old and the deeper layers were deteriorating. The underground drainage system needed to be renovated too, due to clogging. Thus, the SLC was planning to dig up the whole ground and redo it from scratch. As a result, the Compaq Cup matches would be the last matches under lights to be played on the old pitches and the next time an international match would be played at the Khettarama stadium, it would on newly laid pitches. It seemed the Khettarama pitches were going to carry their secrets to the grave.

The authors were requested to carry out an investigation in to the possible causes for the behaviour of the Khettarama pitches by the SLCC on the initiative of Mr. Janaka Sampath, the senior technical officer in charge of pitch preparation, before the grounds were to be renovated. The authors had carried out a research on the behaviour of Sri Lankan cricket pitches [2] with the help of SLC just a few months before this incident.

\section{Pitch Testing}

Nawagamuwa et al., [2] discussed that the playing character of a pitch depends on several parameters.

- Clay and silt content of the soil

- Clay mineralogy of the soil

- Moisture content of soil

- Degree of compaction or density

- Nature of grass on the pitch

Out of these parameters, the only one which can change significantly during the course of 100 overs is the moisture content of the soil. Thus, it was on this parameter that the testing was focussed on.
A sample pitch was prepared by the groundsmen, as exactly would be prepared for an international match. The testing methodology was to gather soil samples from the pitch at one hour time intervals over the time of a day/night One Day International (ODI) match usually played at the stadium. Steps were taken to ensure the test conditions were exactly as would be during an actual day/night ODI including starting time, finishing time and artificial lights.

The exact procedure is as follows:

- Samples from the top dressing of the pitch were extracted at 1 hour time intervals from $2.30 \mathrm{pm}$ to $10.30 \mathrm{pm}$. This time period of 8 hours is usually the same time period being used for a day and night match.

- Two sets of samples were extracted and both were tested for their moisture content. One set of samples were checked for moisture with the top grass layer intact while the other set of samples were checked for moisture without the top grass layer. Samples were obtained by driving cylindrical cores, which were of $100 \mathrm{~cm}^{3}$ in volume.

- Soil samples were extracted to find the density of the pitch top dressing.

- Bounce tests were carried out at the same time intervals at distances of $2 \mathrm{~m}$, $4 \mathrm{~m}$ and $6 \mathrm{~m}$ (Figure 1) from the batting crease at each end. The test was carried out by dropping a cricket ball (a white Kookaburra) from a height of $2 \mathrm{~m}$ and repeated 5 times for each location.

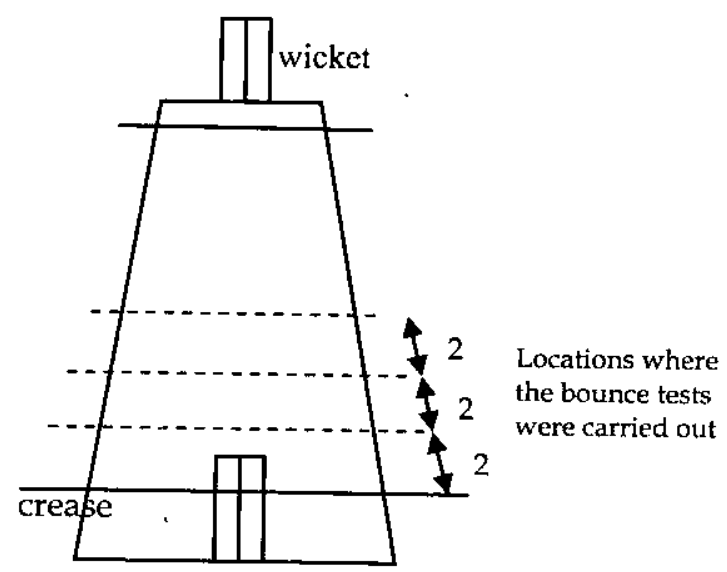

Figure 2: Location on the pitch where tests were conducted 


\section{Bounce Test [3]}

In order to find the coefficient of restitution of a surface, a cricket ball is dropped from a certain height ' $H$ ' and the rebound height ' $h$ ' is measured. From simple mechanics, it can be

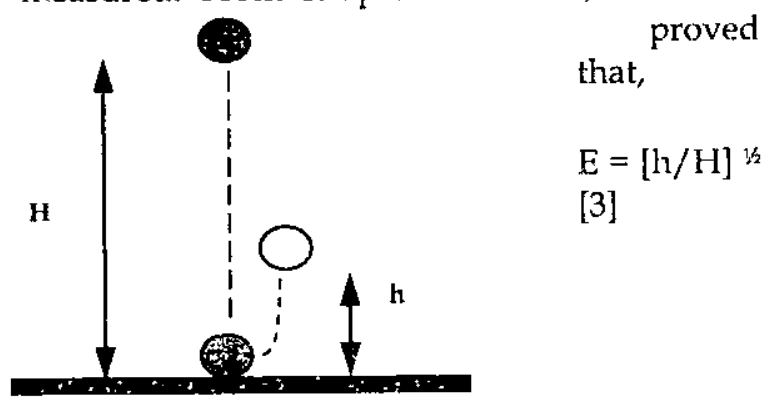

Figure 3: Bounce Test

\section{Results and Data Analysis}

Table 1: Test Results

\begin{tabular}{|l|l|}
\hline \multicolumn{1}{|c|}{ Property } & \multicolumn{1}{|c|}{ Result } \\
\hline $\begin{array}{l}\text { Moisture Content } \\
\text { Range }\end{array}$ & $\begin{array}{l}20 \%-22 \% \text { (Grass } \\
\text { cover included) } \\
16 \%-19 \% \text { (Grass } \\
\text { cover not included) }\end{array}$ \\
\hline $\begin{array}{l}\text { Bulk Density of Pitch } \\
\text { Soil }\end{array}$ & $\begin{array}{l}1500 \mathrm{~kg} / \mathrm{m}^{3}-1600 \\
\mathrm{~kg} / \mathrm{m}^{3}\end{array}$ \\
\hline $\begin{array}{l}\text { Dry Density of Pitch } \\
\text { Soil }\end{array}$ & $\begin{array}{l}1250 \mathrm{~kg} / \mathrm{m}^{3}-1300 \\
\mathrm{~kg} / \mathrm{m}^{3}\end{array}$ \\
\hline $\begin{array}{l}\text { Coefficient of } \\
\text { Restitution (e) }\end{array}$ & $0.45-0.53$ \\
\hline $\begin{array}{l}\text { Rebound Height (Drop } \\
\text { Heigint }=200 \mathrm{~cm} \text { ) }\end{array}$ & $42 \mathrm{~cm} \mathrm{-56 \textrm {cm }}$ \\
\hline
\end{tabular}

Figure 4 shows the moisture variation with time in the topdressing of the pitch. Results "with grass" indicate that the samples were at the location directly on the pitch while "without grass" indicates locations below the grass/vegetation layer. As expected the sample with grass had more moisture but there was particular pattern to the variation. However, a clear trend was evident in the sample without grass. The trend can be seen more clearly in Figure 5 and it shows that the moisture decreases until around $4.30 \mathrm{pm}$ at which point in time the moisture content is the lowest and then increases gradually until around $10.00 \mathrm{pm}$.

This variation is probably due to the accumulation of dew as the evening progresses. The formation of dew on the day of the test was very slight but even then the moisture variation is clearly visible.

In Figure 6, the variation of the coefficient of restitution (e) is plotted together with the moisture variation. It can be seen very clearly that the variation in ' $\mathrm{e}$ ' follows the variation in moisture. This confirms that the nature of the pitch is indeed changing as the evening progresses and it is linked to the moisture in the pitch.

Moisture Variation with Time

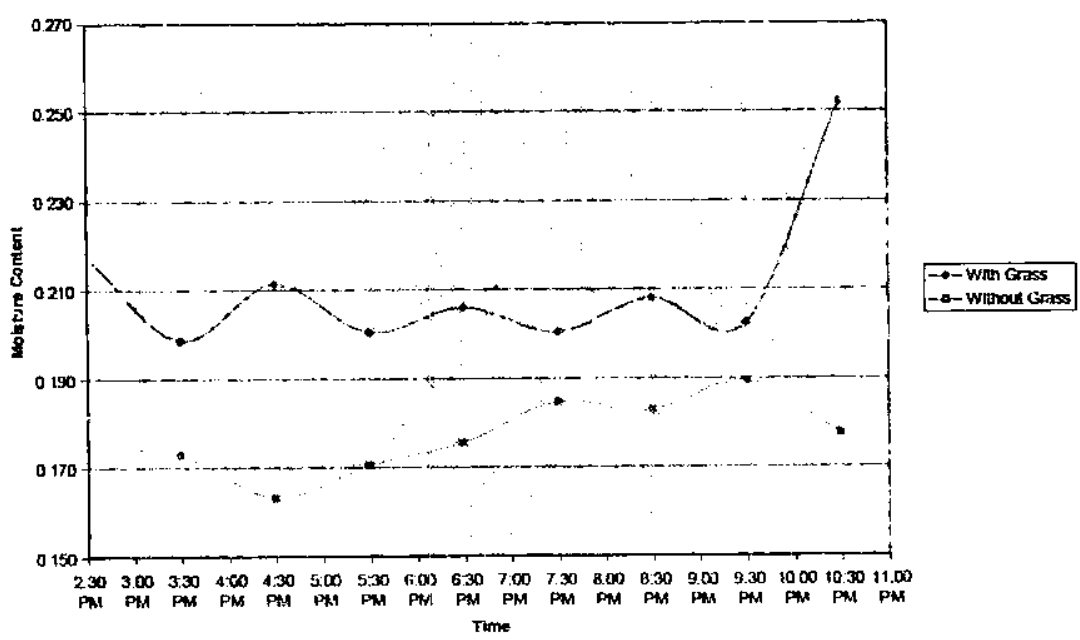

Figure 4: Moisture variation with time 


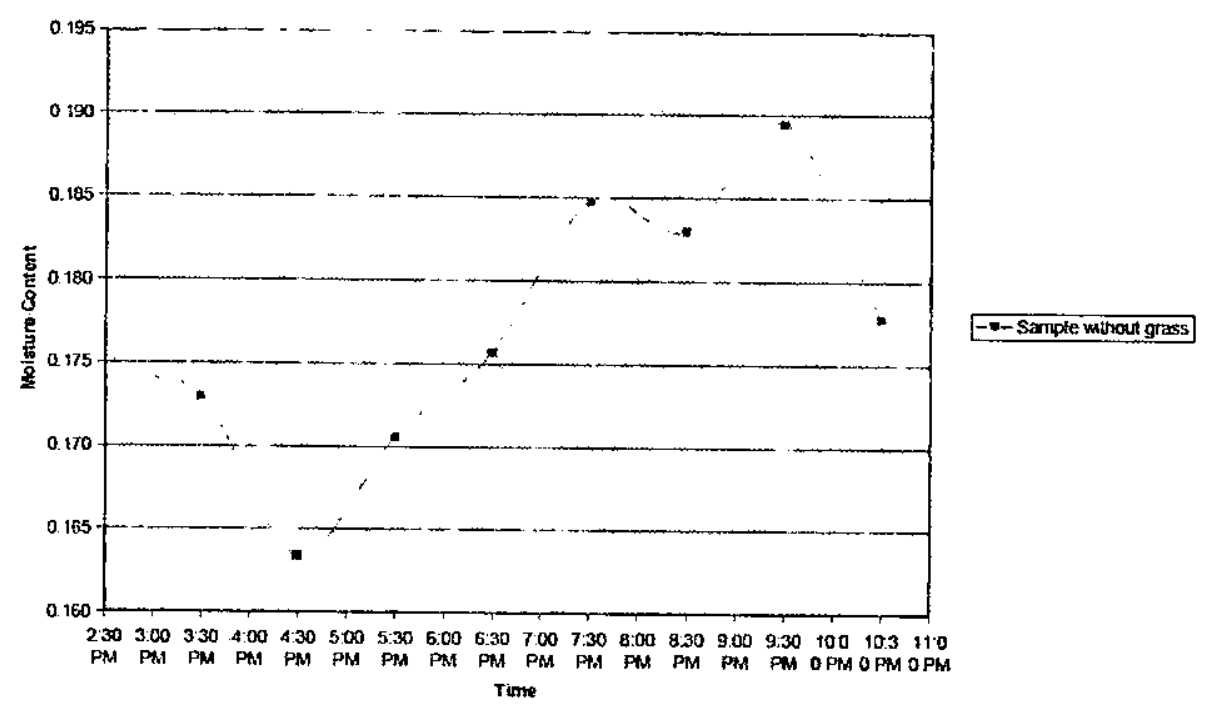

Figure 5: Moisture variation of samples without grass with time (enlarged)

\section{Bounce vs Time}

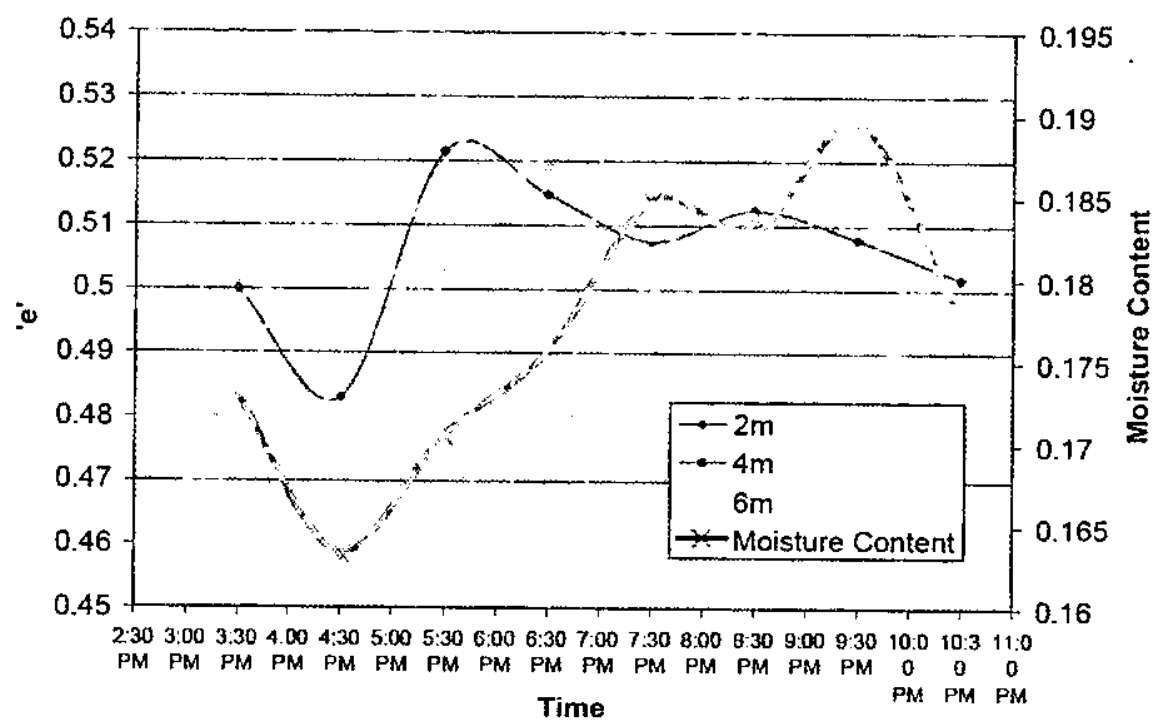

Figure 6-Variation of ' $e$ ' and moisture with time

\section{Hypothesis developed using} unsaturated soil mechanics and soil science

From Figure 6, a clear observation can be made on the relationship between bounce and the moisture content. These results suggest that the bounce (coefficient of restitution, e) is a function of moisture content $(\omega)$ of the soil beneath the grass/vegetation cover.

$e=f(\omega)$

However, this kind of relationship could be justifiable for any cricket pitch in the world. Hence, it is indeed necessary to study the curious behaviour at Khettarama cricket pitch. From Figure 6, it can be observed that the maximum moisture content had been present from 7.00 PM to 9.30 PM. Further, this was the time period for the maximum bounce too. Figure 7 (a), (b) and (c) show some results of cricket matches played at the same venue and noticeably the team batted second had lost more than $50 \%$ wickets between over no 10 to 30 as shown in Table 2. This period perfectly matches with the time having high moisture content and higher bounce. Now it is necessary to study why this pitch is behaving differently than other pitches in the world playing day and night matches. 
Table 2. Analysis of Pattern of Play

\begin{tabular}{|c|c|c|}
\hline Match & Period & Wickets \\
\hline $\begin{array}{c}\text { SL vs NZ } \\
\text { (Figure 7a) }\end{array}$ & Overs 10 to 30 & 4 \\
\hline $\begin{array}{c}\text { SL vs India } \\
\text { (Figure 7b) }\end{array}$ & Overs 10 to 30 & 6 \\
\hline $\begin{array}{c}\text { SL vs India } \\
\text { (Figure 7c) }\end{array}$ & Overs 10 to 30 & 5 \\
\hline
\end{tabular}

(Source [1])

Milanov [4] explained that the content of water in soil changes with time partly depending on the existing meteorological conditions, partly on the kind of vegetation and its stage of development. It was further added that the variations of moisture in a certain soil-volume depend on the relation between the quantity of the water added by infiltration of precipitation water and by moving subsoil and capillary water and the quantity which is subtracted by evaporation, transpiration and drainage. Then Stormont and Coonrod [5] verified the effect of the presence.of shallow ground water table. As it says, soil evaporation is maximized if there is a shallow water table, a hot and dry climate, bare surface exposed to sunlight and wind and a uniform fine grained soil. Perhaps the most important factor in the amount of soil evaporation is the proximity of the water table. If the water table is very shallow (within a meter or so) water will be continually supplied from the water table upward to the soil surface. This type of evaporation is often termed water table evaporation. In this case, soil evaporation is largely controlled by climatic conditions at the soil surface.

As this curious Khettarama pitch was constructed on a swampy/marshy land, this behaviour can be expected after drying out of the pitch in the afterncon. A similar variation of temperature and humidity at R. Premadasa stadium on a day in the month of May is shown for easy reference in Figure 8 [6]. As this variation indicates, moisture movement due to capillary action would be prominent and then the effect due to moisture content will be high after the peak around 6PM.

Another approach in discussing this situation could be done considering stiffness effect of the pitch. It could be sensitively and reasonably assumed that the stiffness (G) of the pitch governs the bouncy nature.

Hence, $e=f(G)$
Roberson [7] stated using field data that most soils compacted above the water table never reach saturation and thus normally remain in an unsaturated state. Moreover, Gupta and Ranaivosan [8] explained that the moisture and suction regimes of unsaturated soils can vary in response to the loading and environmental conditions while in service. The stiffness is greatly influenced by the state of stress and is also sensitive to the moisture and suction variations. If the stress could be same in all other comparable pitches, then at the Khettarama pitch, unusual behaviour due to stiffness would be mainly governed by the moist and suction variations. This could be even more critical due to the presence of shallow ground water table at this location.

\section{Conclusions}

Moisture in the topdressing of the pitch changes with time. The general trend suggests that it starts to increase once the sun sets and the temperature drops. Bounce test results confirm a change in the nature of the pitch. However, a bounce test alone cannot completely predict the performance of a pitch. Therefore, the results cannot say whether there is an advantage in batting first or second, it can only say that the conditions are different for each inning.

The test results imply that a correiation between the coefficient of restitution and the moisture content of the soil exists but, this is based on tests carried out on a single day/night and on a single pitch. This means the statistical validity is low but the trends which were found are very clear and cannot be disregarded either. A longer term study would be able to give more statistically acceptable data as well include seasonal variations in pitch behavior due to changes in weather conditions.

In addition to the field observations at Khettarama pitch, there is a theoretical basis on the variation of the moisture movements especially after the sunset. Since the presence of swampy/marshy land below the pitch, it must be very much needed to isolate the pitches from the shallow ground water table to mitigate the moisture movement effects due to capillary action. Further, proper drainage facilities would be required in removing excess water during a heavy rainfall while an isolation system between shallow water table and the pitch is in use. 
or Lanka won by Gliuns

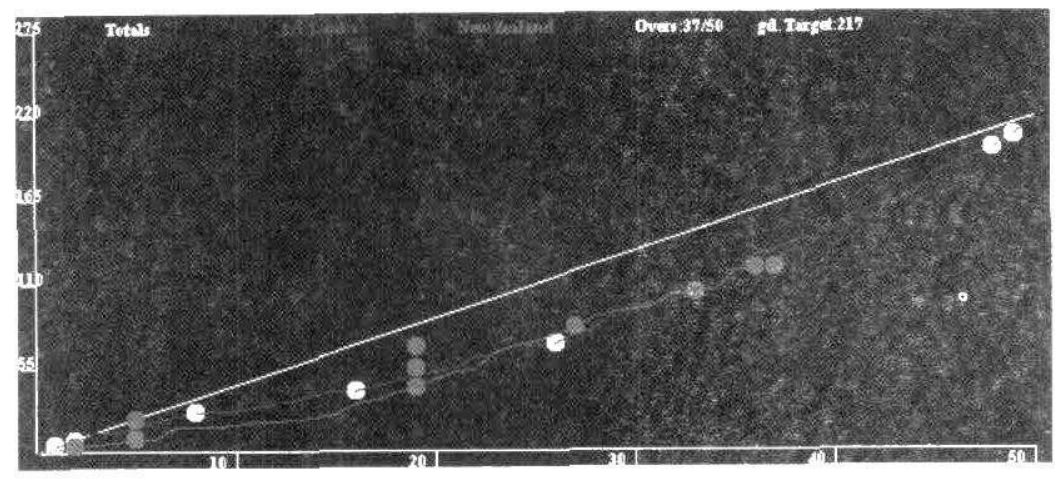

Figure 7(a)

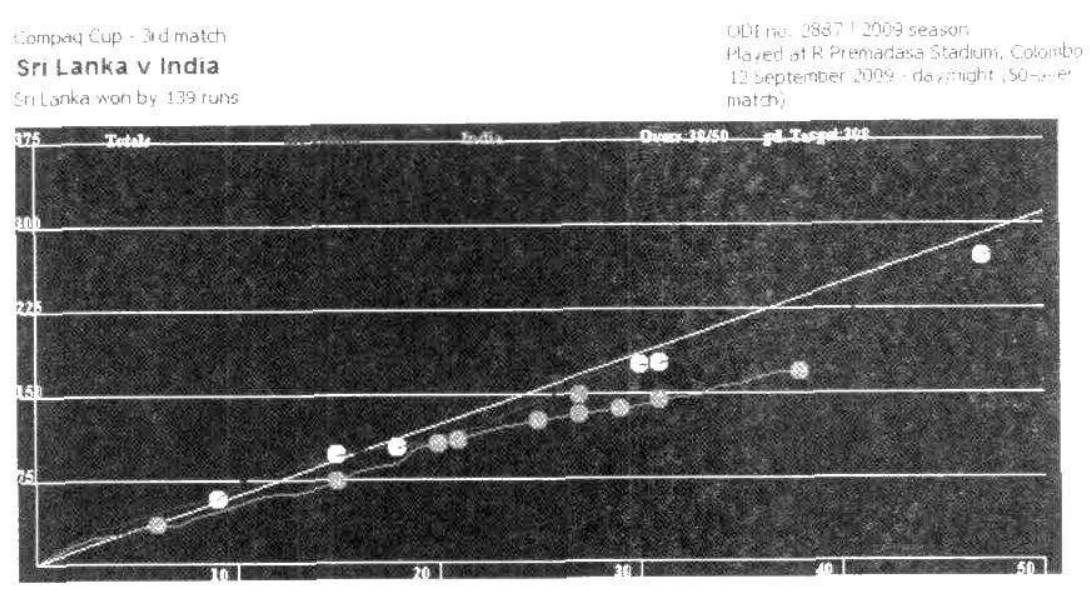

Figure $7(\mathrm{~b})$

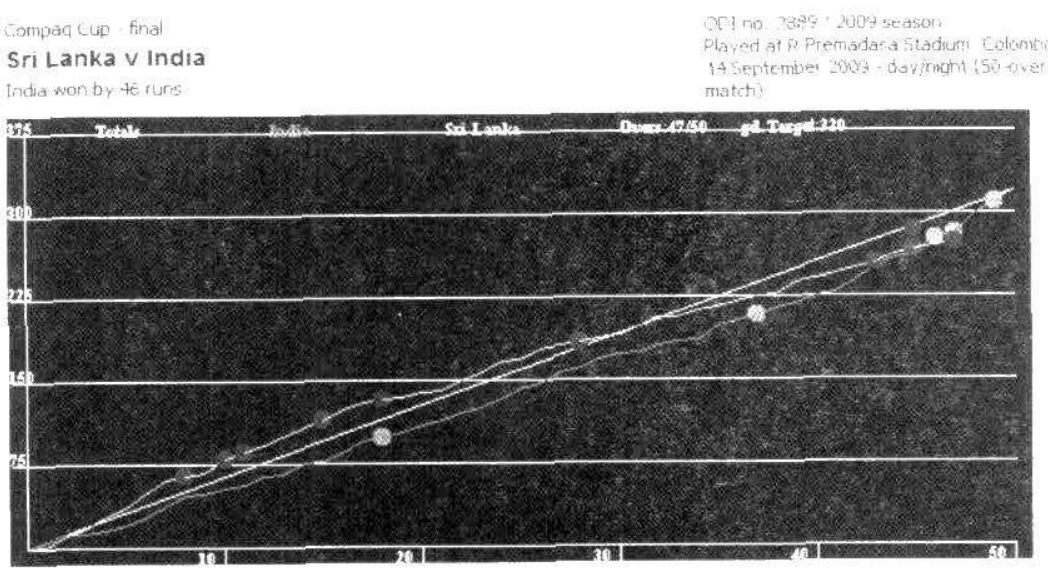

Figure $7(\mathrm{c})$ 


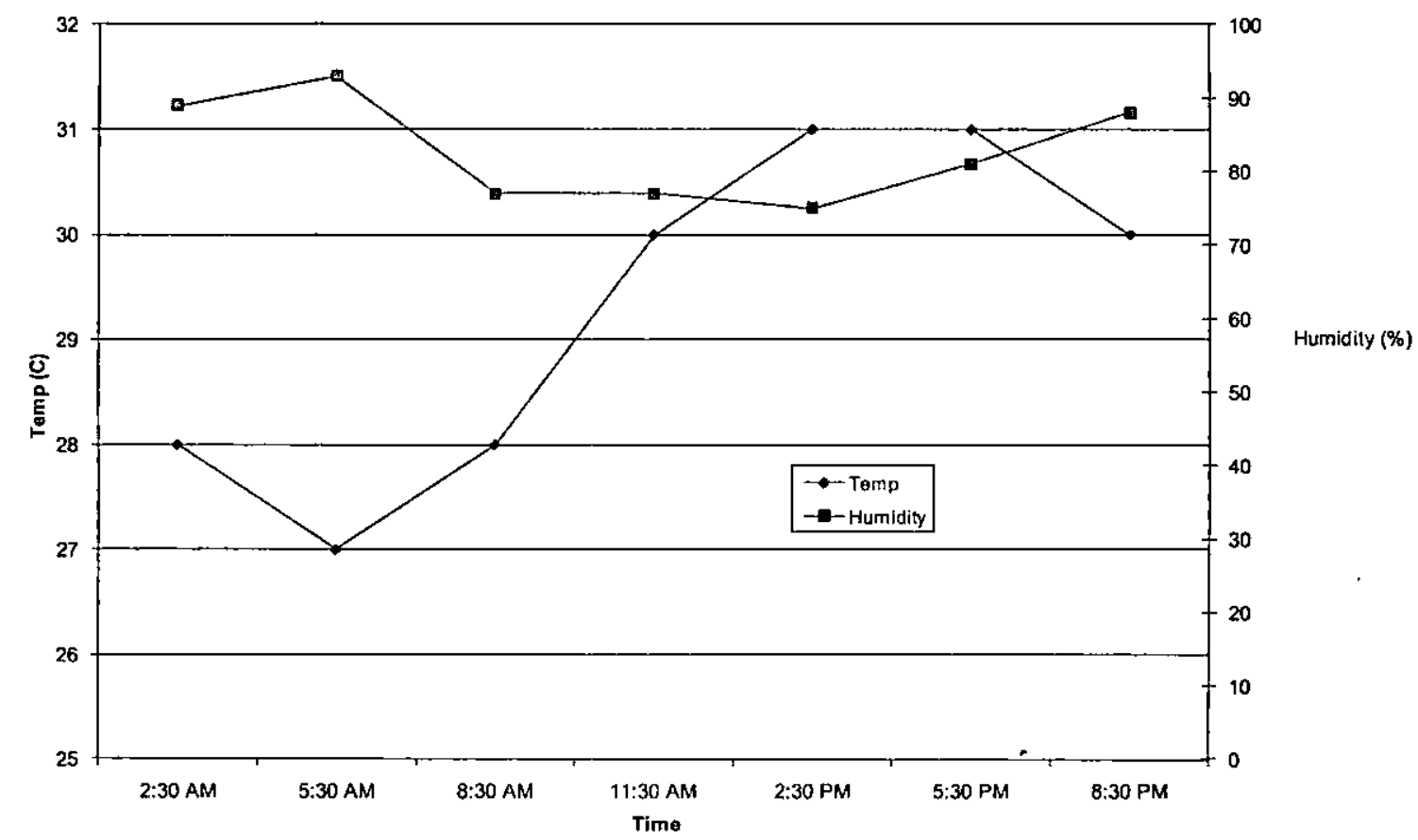

Figure 8. Temperature and humidity variation in a day of month May [6]

\section{Acknowledgement}

The authors wish to thank Mr. Janaka Sampath, Senior Technical Officer in charge of pitch preparation at SLC, who was instrumental in starting this study and who provided all the background support to carry out the testing. They would also like to thank Mr. Asanka Herath, Junior Curator at the Khettarama Stadium and the groundsmen who were a great source of help during the testing of the pitches.

\section{References:}

\section{[1] www.cricinfo.com}

[2] Nawagamuwa, U.P., Senanayake, A.I.M.J., Silva S.A. \& Sanjeew D.M.I., Improvement of local soils in order to make "fast \& bouncy" cricket pitches, ENGINEER, Journal of the Institution of Engineers, Sri Lanka, Vol XXXXII, No 04, October 2009

[3] James D.M., Carre M.J. and Haake S.J. (2005) Predicting the playing character of cricket pitches Sports Engineering (2005) 8, 193-207

[4] Milanov, T. (1970), An estimation of evapotranspiration by means of the water balance of a soil column, Nordic Hydrology, 1970, pp 141-149

[5] Stormont, J.C., and Coonrod, J. (2004), Water depletions from soil evaporation, Identifying technologies to improve regional water stewardship: North-Middle Rio Grande Corridor, 21-22 April 2004

[6] Weather forecast for $R$ Premadasa Stadium, www.myweather2.com/cricket/SriLanka/R-

Premadasa -Stadium

[7] Roberson, R. (2002), "Material Moisture Characterization," Seminar on Unsaturated Soil Engineering: Applications in Pavements, Minnesota Department of Transportation, MN.

[8] Gupta, S. and Ranaivosan, A. (2007), Pavement design using unsaturated soil technology, Research 2007-11, Minnesota Department of Transportation, Minnesota 55155 